\title{
The Extent to which Public Private Partnerships Enhances Good Performance of an Entity
}

\author{
Submitted 11/07/21, 1st revision 13/08/21, 2nd revision 29/09/21, accepted 28/10/21
}

\author{
Chidochashe Joanna $\mathrm{M}^{1}$, Wadesango Newman ${ }^{2}$, Malatji Stephen Khashane ${ }^{3}$, \\ Sitsha, L. ${ }^{4}$
}

\begin{abstract}
:
Purpose: The purpose of the study was to establish the effectiveness of public-private partnerships $(P P P)$ in enhancing the performance of an entity, challenges faced in implementing PPP, and the extent to which the resources support through PPP affect performance in road services delivery.

Design/Methodology/Approach: A desktop approach was used. The study made use of secondary data.

Findings: The study established that factors that influenced companies to adopt PPPs were, the need for financial resources, infrastructure development, improving efficiency, reducing poverty, and fueling economic growth.

Practical Implications: The study concludes that contract renegotiation, performance enforcement, political acceptability, lack of sound regulatory framework was some of the challenges prevailing. The study offers six policy recommendations to improve the performance of SEPs in Zimbabwe.

Originality/Value: It considers the fact that PPP reduces pressure on government budgets due to the use of private financing for infrastructure and provides better value for money in public infrastructure provision.
\end{abstract}

Keywords: ZINARA, public private partnerships, entity, road service delivery.

JEL Codes: $C 1, C 4, C 5$.

Paper type: Research article.

\footnotetext{
${ }^{1}$ Midlands State University, Zimbabwe; mawirec@msu.ac.zw;

${ }^{2}$ Prof., University of Limpopo, South Africa; newman.wadesango@ul.ac.za;

${ }^{3}$ Tshwane University of Technology, MalatjiKS@tut.ac.za;

${ }^{4}$ Midlands State University, Zimbabwe: sitsha2005@gmail.com;
} 


\section{Introduction}

This study reviewed literature from areas where PPPs have been used in the region and the world. The paper started by defining the PPPs and then look at the schemes of PPP available. The research also reviewed the literature on the benefits and challenges of PPPs and the capacity of both parties, thus the private company and the SOE.

Public-private partnerships PPPs have become widely accepted and prevalent in managing the public sector. Reviewing various definitions indicates that there is no accurate agreed definition of PPP. There are nonetheless standard features across the various approaches as well as distinctive features. Several gaps were found concerning PPP governance, management, and policy design issues. A popular way to define PPP is as an instrument of governance or management. The dominant theme is that PPP offers a modern approach to providing products and services to people, and the innovation is the managerial and governing style (Hodge and Greve, 2015; Wadesango et al., 2016). The authors who use this approach to PPP tend to focus on the relation's organizational aspects. Most of the concepts that focus on management and governance methods emphasize that PPPs are inter-organizational or financial relationships between the public and private actors.

\section{Literature Review}

One definition of PPP is provided with the lens of organizational relations by Dutch public-management scholars Van Ham and Koppenjan (2011). They identify PPP as some lasting cooperation between public and private actors in which they jointly develop products. This concept has many characteristics. First, it emphasizes specific longevity cooperation, where collaboration cannot occur only in short-term contracts. Broadbent and Leaughlin (2013), Carr (2018), and Bovaird (2014) support that collaborative feature. Second, it emphasizes risk sharing as a crucial component. Both parties must carry parts of the risks involved together in a partnership. Third, they produce something together (a product or service), and maybe implicitly, both gain from the mutual effort.

Similar features are evident in the definitions provided by the PPPs (Klijn and Teisman, 2010; 2015) and the UK Public-Private Partnerships Commission (2011), Where PPPs are defined as a sustainable partnership between public and private actors in which joint projects and/or services are established and in which risks, costs and profits are shared (Klijan and Teisman, 2010; 2015) and as a 'risk-sharing arrangement between public and private companies - including voluntary sector to achieve the desired outcome of public policy '(Committee on Public-Private Partnerships for the UK, 2011). Stratton's (2019) definition is very similar, though, in private sectors, Stratton has included 'business and non-profit sectors.' Salamon (2015) supports this too. 
Some PPP definitions emphasize financial relationships (Wadesango and Mhaka, 2017). There are promises that PPP reduces pressure on government budgets due to the use of private financing for infrastructure and provides better value for money in public infrastructure provision. In infrastructure building literature, these uses of PPPs are prominent. In infrastructure building literature, these uses of PPPs are prominent. These include, for the most part, BOT (Build-Operate-Transfer), BOOT (Build-OwnOperate-Transfer), and BOO (Build-Own-Operate). The most common of these arrangements is BOT Campbell (2011), suggesting a definition of PPP that focuses on financial arrangements that are 'a PPP project generally involves the design, construction, financing, and maintenance and sometimes the private sector's operation of public infrastructure or a public facility under a long-term contract.

The prominent arguments are PPPs maximizing development benefits through collaboration (World Bank, 2019) and improving efficiency (Brinkerhoff, 2012). Thus, PPP is viewed as an essential method of promoting development (Agere, 2010) and a development tool (Paoletto, 2010). A commonality in these definitions is that the government widely discusses the concept of PPPs as a gap-filler toward infrastructural development. However, it must be noted that the punch of PPPs in infrastructure projects largely depends on the extent to which the government effectively controls the private partners providing private partners with sufficient operational autonomy.

Benefits of public-private partnership that will help in enhancing the performance of ZINARA. Evidence on the ground generally points to solid penetration of PPPs in public infrastructure as immediate solutions to the ongoing problems faced by most governments in infrastructure networks in their respective countries, as well as to enhance the delivery of quality services (Farlam, 2015; Wadesango, Mhaka and Wadesango, 2017). Most of them are optimistic about applying the PPP model, where the government shares risk and responsibility with private partners, but ultimately retaining asset control will go a long way towards improving services, while at the same time avoiding some of the privatization pitfalls, unemployment, higher prices, and corruption. Hopes were firm that PPPs would turn around poorly performing public utilities by bringing in new talent, financial capital, and a more entrepreneurial focus. As has been widespread in the literature, the definition of PPPs can never be ignored as a remedy for government failures in carrying out its sovereign duties, especially in this context of limited fiscal space and rapid urbanization, and an increase in the population.

According to Jerome (2014), African governments' constant malfunction in delivering essential goods and services to the public is well documented but not remedied. Furthermore, studies from the UK, where the Private Finance Initiative (PFI) was, have shown that cost savings by private organizations providing public services have changed the terms of employment, thereby reducing the costs of providing services. Therefore, the advantages and benefits of PPPs cannot be overlooked and must be carefully considered by the governments. Implicit is that PPPs give the ability to tackle 
public sector inefficiency and waste (Harrel, 2013; Wadesango, Mhaka and Wadesango, 2017). In this regard, (Farlan, 2016) concludes that the tax benefits of selling or leasing state-owned enterprises (SOEs), including reduced subsidies to these often-loss-making entities or new investment governments that cannot afford to provide on their own. He added that there is also the benefit in productivity of the private sector, which can lead to lower prices and improved access for more of the population, the growth of the local financial system, and increased development of the private sector, which includes expanding local participation.

The nature of partnership a state-owned enterprise can engage in with a private company to enhance its performance: There is a range of PPP schemes that can be taken up by an SOE in collaboration with a private sector to improve the SOE's performance, depending on the nature of the SOE's engaged infrastructural project (Farrel, 2015). Such models include the Build and Transfer Scheme (BT), Build Operate and Transfer Scheme (BOT), Build and Operate (BTO), Rehabilitate Operate, and Transfer (ROT), and Lease Develop and Operate (LDO) (Dube and Chigumira, 2011). The Nepal Planning Commission Paper (2009:8) highlighted the same PPP models but added the Develop Operation and Transfer (DOT) model. ADBI 2011:19 includes the Design Build Finance and Operate (DBFO) model.

\section{Discussion}

The underlying principle of this scheme is that the private sector is providing finance for the construction of the infrastructure and then handing it over to the government upon completion (Harrel, 2013). The government would then repay the agreed finances, and the private player would repay the reasons. The possibility of using this scheme in road construction or road rehabilitation is evident when we look at the case in context.

Challenges associated with public, private partnership: Farlam (2015) suggests that the government needs to essentially improve its relationship with private actors to realize the benefits that these partnerships can bring. Therefore, to access these benefits, there is a need for good relations, which means that if relations are not good, there arises a problem or, better so, a challenge that can hinder the partnership's success. Khatees (2012) also supported this notion as he said, there ought to be good relations between the partners for a successful partnership. Linder (2018) argued that a PPP is a business deal, it does not matter if the two parties involved have no excellent relation if they have written arrangement, that can permanently settle their conflicts because a company cannot let good business go away even if it is coming from an unwanted source. Therefore, this challenge is left unanswered because researchers are coming up with different perspectives on the issue.

PPPs are expected to be a cash cow to both companies (Luady, 2015). However, they are not immune to criticism. Among the demerits that they suffer include the fact that they require high capacity, are mainly financed with debt over a long period, and are 
generally sensitive to high-level risks. According to Shediac (2018) although PPPs can complement government resources for other public needs, the main concern is that they will not essentially influence the economy without including the right mix of factors. The value, type, and number of PPPs, combined with accommodative policies, power, economic growth. While general recognition of the potential role of PPPs in advancing transportation development goals, the lack of evidence-based outcomes means these collaborations still face numerous criticisms and possible downturns.

Financial issues: Financial problems common to all forms of PPP include longer payback times than anticipated, lower than expected returns on investment, local support for maintenance operations, diminishing revenues, and rising inflationinduced costs. It can be difficult to estimate costs accurately, particularly when inflation rises above the level foreseen in the partnership agreement (Waetz, 2017). To resolve this problem and avoid spiraling costs out of control, meetings should be held to renegotiate all partners' contributions to appropriate rates.

Social and environmental sustainability issues: In PPPs, the chance of excluding small-scale actors, such as smallholder firms, is always a possibility. Private investors may choose to work exclusively with larger firms to minimize transportation costs or opt for the vertical integration of production into their operations to achieve social goals (Qatra, 2013). Specific programs, such as the productivity initiatives for PPP in Latin America, concentrated primarily on the participation of SMEs.

Clash of cultures and desires, some cases show that "unwilling allies" remain local governments and civic and NGO organizations. Although examples of strengthened partnerships are recorded substantial reflecting changes in themselves, the mindset of 'us and them' presents a significant challenge for collective action. This is compounded by the legacies of centralization and exclusivity, preferential care, and competition between different stakeholders. As societies grapple with processes of democratization and decentralization, political instability also contributes to complex conditions. Mamelodi (2012) says new relationships of confidence must be formed between stakeholders who remain wary of one another.

Private businesses should work with State-Owned Enterprises to increase the efficiency of the SOE if these measures are considered to enforce PPPs successfully. (Abdel, 2017) addresses the criteria to be followed to ensure effective implementation of the PPP program. These principles include understanding the objectives of using private finance when selecting a PPP arrangement, properly allocating risk to the private sector, establishing a comprehensive legal framework for PPPs, assessing the value for money when selecting a delivery system, creating a PPP unit for policy development and implementation, and maintaining sector transparency.

Beck et al. (2013) concluded that factors leading to achieving the highest value in PPP projects are comprehensive risk analysis and effective risk distribution, promoting faster project management, curtailing project cost escalation, promoting project 
creation creativity, and sufficient maintenance cost transparency. Researchers have found the factors hindering the acquisition of the highest value in PPP contracts to be lengthy and complex discussions on the high cost of the PPP procurement process, difficulties in deciding the quality-of-service costing of facilities management firms, possible conflicts of interest for those involved in the procurement process and public sector reluctance of clients to handle consultants. Charoppatan and Minato (2019) proposed risk allocation strategies for five risk categories: political, economic, legal, transactional, and operational. Durchslag et al. (2014) studied a set of conditions to be met for the long-term success of the PPP.

These requirements were found to ensure maximum engagement and encouragement from the highest political authorities to move the system as rapidly as practicable, improve accountability and reduce the room for discretionary decision making to maintain process integrity, optimize government incentives, incentive and credit provisions, empower a small committee of making careful decisions, creating and implementing the legislative and regulatory structure of the sector before any actual securitization or sale takes place, ensuring the fairness of the reform process and optimizing competition by using public tenders.

Performance: To determine whether PPPs can enhance the performance of ZINARA, it is necessary to measure ZINARA's performance after the partnership has been done, and here are some ways to measure an entity's performance.

Measuring performance (efficiency): Output evaluation can be defined as "the method of quantifying the effectiveness and efficiency of intervention" (Neely et al., 2015). Kaplan (2010) contends that measuring performance is a prerequisite for performance improvement. A series of studies have led to the centric growth of performance evaluation in the last two decades with this objective (Gunasekaran and Kobu, 2017). Success assessment is explicitly used to assess an organization's performance (Kennerley and Neely, 2014). History can be traced back to the medieval era when the calculation of "time" output was used predominantly in organizations under the early modern accounting system and dual entry accounting scheme (Johnson, 2013; Bruns, 2018). Due to the development of organizations in terms of ownership separation and management and financial measures, specific returns on investment, cash flow, and profit margin in the 1900s gradually replaced the dominant position of "time assessment" (Kennerly and Neely, 2014). By the 1980s, there was a growing perception that sole financial measures were no longer sufficient to measure the performance of organizations in both academics and industry in the modern corporate environment (Kaplan and Norton, 2016). Companies need to adapt more to industry trends and long-term results to statistical customer expectations and recover market share since the competitive markets (Parker, 2010).

Measure the efficiency of PPP ventures: As discussed above, quality assurance has gained substantial popularity and is now being implemented in various areas such as engineering, business service, logistics, and supply chain (Skinner, 2014). Quality 
assessment is also essential at the project level and relates directly to project progress realization in PPP projects (Yong, 2010). Strategic goals from the basic success assessment (Solomon and Yong, 2017). The primary strategic goal of PPP infrastructure projects is to maximize efficiency, value for money (VfM), and performance standards (Antitoye, 2013). The strategic target includes topics related to the public client's overall strategic plan and mission priorities, the private sector's long-term growth and payoff strategy, quality public services, and the general public's service needs (Yuan et al., 2019).

VfM is the core Best Value Factor, which has been used as the key benchmark for the strategic objective of PPP (Akintoye et al., 2013). UK's Treasury Task Force (2018) says PPPs can be used only when they offer stronger VfM than conventional procurement. Essentially, VfM can be defined as the optimum combination of the entire life cost and the user's quality (Office of Government Commerce, 2012).

The future direction of PPP performance assessment life cycle assessment under PMS: It was found that short process estimation and product-oriented assessment are two significant problems with current measurements of PPP performance. Depending on this result, PPP evaluation should be based on a complex process (life cycle analysis) where measurement is a priority on each project phase compared to the simplistic product-based metric. The life cycle process-based assessment can capture the complex function of the project processes and providing real-time monitoring of the process and the overall output of the project (Liu et al., 2013).

Haponava (2010) was first proposing a method-based assessment for a general construction project. It is a framework that incorporates a series of process based KPIs. KPIs are measured, indicating a matched performance of the processes (Beatham et al., 2014). Given the widespread construction of KPIs, (Songer et al., 2016) nevertheless earned several requirements. For example, KPIs are concerned with project performance rather than company performance, and it is not possible to address long-term corporate issues (i.e., strategies) adequately within the KPI framework (Bassioni et al., 2014).

One essential principle in performance evaluation is that performance metrics must be the context in which they are being applied (Neely, 2019). Special Purpose Vehicle (SPV), a group responsible for production, construction, operation, and management of long-term contract procurement public properties, typically performs a PPP (Moszoro et al., 2018). Essentially, SPVs have a dual character indicating that they work to achieve client targets and project rates (Yong, 2010). In other words, the evaluations for PPPs will focus on the results at the level of the client and the project in a long-term context.

PMSs demonstrate a greater capacity for integrated calculation compared to KPIs since they are the frameworks that require strategic and operational long-term steps 
(Chamorro et al., 2013). PMSs were used for manufacturing, business, and projectlevel measurements in construction (Alarcon and Ashley, 2016). Against this contextual backdrop, PPPs consider method-based evaluation more feasible integrated with PMSs than using KPIs. The BSC has undeniably been the most reputable PMS used widely across industries over the past two decades (Gunasekaran and Kobu, 2017; Wadesango et al., 2017). Most PMSs produced in construction research come from BSC (Bassioni et al., 2015). From a stakeholder perspective, the BSC is not broad enough, integrating only consumers and shareholders and neglecting vendors, partnership partners, staff, regulators, and local community or pressure groups, all of which are vital to the efficiency or success of an organization/project.

\section{Conclusion}

Factors that motivated ZINARA to implement PPPs were the need for financial capital, expanding infrastructure, increasing productivity, reducing poverty, and accelerating economic development. In implementing PPP with Group Five, ZINARA faced challenges such as contract renegotiation, performance enforcement, political acceptability, lack of a sound regulatory framework, lack of fulfillment of key training requirements, lack of common vision and win-win relationships, multiple key participant interests, and conflict between public and private sector officials in PPPs.

The capacity of Group Five to venture into this partnership was demonstrated by the funds, experience, and good communication it brought in. PPPs also supported the success of ZINARA in the provision of road services by safe travel to road users, better road safety, more road amenities, enhanced road service reliability, clean and attractive highways, increased revenue generation and better cost control strategies.

\section{References:}

African Development Bank (AfDB). 2011. Infrastructure and Growth in Zimbabwe: An Action Plan for Sustained Strong Economic Growth Report. AfDB, Tunis Belvédère, Tunisia.

Aziz, A., Kassim, P.S.J. 2011. Objectives, success, and failure factors of housing publicprivate partnerships in Malaysia. Habitat International, 35, 150-157.

Grace, C., Duce, N. 2011. External Review of Product Development Partnership Grant Framework. London, UK.

IMF (International Monetary Fund). 2004. Public-Private Partnerships, Washington, DC.

Jamali, D. 2004. Success and failure mechanisms of public private partnerships in developing countries: insights from Lebanon. Emerald the International Journal of Public Sector Management, 17(5), 414-430.

Jong, M., de Rui, M., Stead, D., Yongchi, M., Bao, X. 2010. Introducing public-private partnerships for metropolitan subways in China: what is the evidence? Journal of Transport.

Malik, A.B. 2010. Public-Private Partnerships in Education: Lessons Learned from the Punjab Education Foundation (Asian Development Bank). Retrieved from: https://ppp.worldbank.org/public-privatepartnership. 
McKinsey. 2009. Public-Private Partnerships: Harnessing the Private Sector's Unique Ability to enhance Social Impact.

Miles, M.B., Huberman, A.M. 1994. Qualitative Research Design, second edition. Thousand Oaks CA: Sage Publications.

Ministry of Finance. 2015. Mid Term Fiscal Policy. Retrieved from: http://www.zimtreasury.gov.zw/index.php/ mid-year-fiscal-policyreview.

Muzapu, R., Havadi, T., Mandizvidza, K., Xiongyi, N. 2016. Managing State-Owned Enterprises (SOEs) and Parastatals in Zimbabwe: Human resource Management Challenges-Drawing Lessons from the Chinese experience. DOI: 10.5923?j.mm.20160604.01.

OECD (Organisation for Economic Cooperation and Development). 2008. Public-Private Partnerships. In: Pursuit of Risk Sharing and Value for Money. Paris.

Owned Enterprises (SOEs) and Parastatals in Zimbabwe: Human Resource Management Challenges - Drawing Lessons from the Chinese Experience. Scientific \& Academic Publishing, Beijing, China.

Shediac, R., Abouchakra, R., Hammami, M., Najjar, M.H. 2015. Public-Private Partnerships: A New Catalyst for Economic Growth, Booz and Company. Abu Dhabi.

Wadesango, N., Chinamasa, T., Mhaka, C., Wadesango, V.O. 2017. Challenges faced by management in implementing audit recommendations: A literature review. Risk Governance and Control: Financial Markets \& Institutions, 7(4), 51-61.

Wadesango, N., Katiyo, E., Mhaka, C., Wadesango, O.V. 2017. An evaluation of the effectiveness of Financial Statements in disclosing true business performance to stakeholders in hospitality industry (A case of Lester-Lesley Limited). Academy of Accounting and Financial Studies Journal, 21(3), 1-22.

Wadesango, N., Mhaka, C. 2017. The effectiveness of enterprise risk management and internal audit function on quality of financial reporting in universities. Journal of Economics and Behavioral Studies, 9(4), 230-241.

Wadesango, N., Mhaka, C., Chinamasa, T., Wadesango, V.O. 2017. An investigation into management's reluctance in implementing audit recommendations and its effects to risk. Corporate Board: Role, Duties \& Composition, 13(2), 61-70.

Wadesango, N., Mhaka, C., Wadesango, V.O. 2017. Contribution of enterprise risk management and internal audit function towards quality of financial reporting in universities in a developing country. Risk Governance and control: Financial markets \& institutions, 7(2), 170-176.

Wadesango, N., Nani, L., Mhaka, C., Wadesango, V.O. 2017. An Analysis of the impacts of liquidity constraints on new financial product development. Risk governance \& control: Financial Markets \& Institutions, 7(3), 65-76.

Wadesango, N., Tasa, E., Milondzo, K., Wadesango, V.O. 2016. A literature review on the impact of IAS/IFRS and regulations on quality of financial reporting. Risk Governance and control: Financial markets \& institutions, 6(4), 102-108.

Wadesango, N., Wadesango, O. 2016. The need for financial statements to disclose true business performance to stakeholders. Corporate Board: Role, duties, and composition, 12(2), 77-84.

World Bank. 2012. Support to Public-Private Partnerships: Lessons from experience in client countries. Washington, DC: World Bank. 